\title{
InterANTARCTICA: Tangible User Interface for Museum Based Interaction
}

\author{
Caitilin de Bérigny Wall and Xiangyu Wang
}

\author{
Design Lab, Faculty of Architecture, Design and Planning, The University of Sydney, Australia
}

\begin{abstract}
This paper presents the design and concept for an interactive museum installation, InterANTARCTICA. The museum installation is based on a gesture-driven spatially surrounded tangible user interface (TUI) platform. The TUI allows a technological exploration of environmental climate change research by developing the status of interaction in museum installation art. The aim of the museum installation is to produce a cross-media platform suited to TUI and gestural interactions. We argue that our museum installation InterANTARCTICA pursues climate change in an interactive context, thus reinventing museum installation art in an experiential multi-modal context (sight, sound, touch).
\end{abstract}

\section{INTRODUCTION}

InterANTARCTICA will create an innovative cross-media platform for technological exploration of climate change research by developing the status of viewer-based interaction in museum installations.

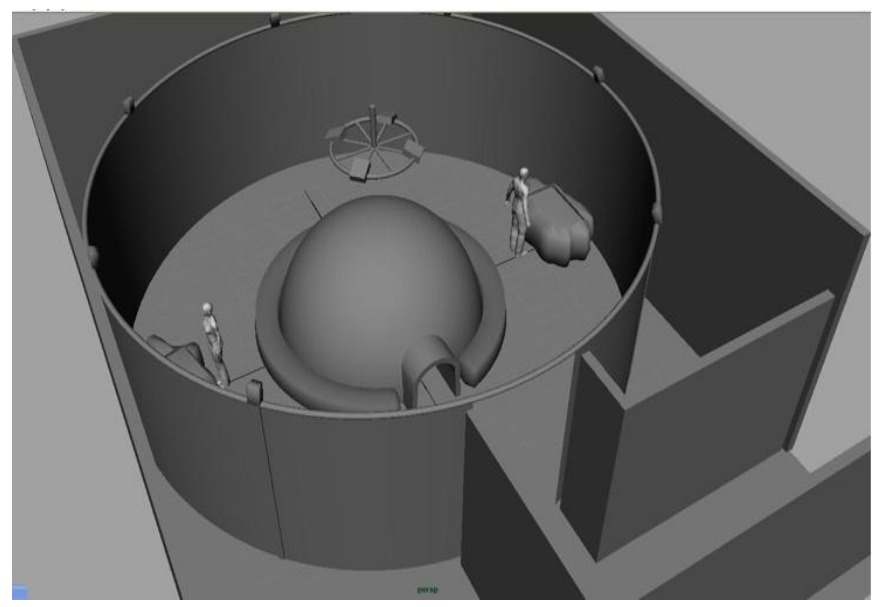

Fig. 1. Ariel view of Museum space; screens enable a curvilinear projection.

\section{INTERANTARCTICA MUSEUM COMPONENTS}

The museum installation InterANTARCTICA has numerous components: panoramic video; Tangible User Interface (TUI) tables; multi-user interactive sound and visualization projected onto a dome.
Entering the museum space the viewer is encircled by four data projections, in a circular constructed site. The installation environment gives the viewer a feeling surrounded by the Antarctica landscape (see. Fig. 2). Encircled by four panoramic screens, the viewer experiences multi-modal senses (sight, sound, touch). Inside the museum space, the viewer hears Antarctic compositions, created by other viewers in real-time audio interaction (see. Fig. 4). Unlike most museum installations, InterANTARCTICA relies on viewer-interaction. The viewer in the museum space controls and creates sound. By creating sound the viewer engages in an additional interaction by modifying a large-scale visualization. Thus, the interactive environment stimulates a multiple sensory experience. The viewer is immersed in the installation via gesture-activated sound and image.

\subsection{Panoramic projection screens}

The panoramic screens display aerial cinematography of Antarctic ice cliffs. Capturing digital video between two Australian Antarctic bases, Casey and Davis (see Fig. 3, top), will encapsulate the vast scale of the majestic ice-cliffs surrounding the continent. The video composition will be filmed in digital HD and edited in Final Cut Pro Studio (FCP), Motion, Color and compositing in Adobe After Effects.

We want to visually emphasize global warming (see Fig. 4 and 5 dome), and the effect it is having on the polar landscape and the world. It is known that sub-Antarctic glaciers are melting at acceleration rates: "In 2002, we witnessed the collapse of much for the Larsen-B ice shelf, a floating slab of ice $200 \mathrm{~m}$ thick and about one and a half time the size of the Australian Capital Territory" [1]. Scientists at the U.S. Geological Survey estimate that if the ice in Greenland and Antarctica melt, global sea level will rise by approximately 65 meters. Furthermore, Climatologist Gerald Meehl et al. claimed that: "...we are already committed to further global warming of about another half degree and an additional 320\% sea level rise caused by thermal expansion by the end of the 21 st century" [2]. The TUI tables and the visualization platform will invoke the effect of global warming by simulating changes in sea level, via real-time viewer interaction.

\subsection{Dome interior/sound compositions}

A large dome is constructed in the centre of the installation with a diameter of 4 meters. The exterior has a projection of a virtual map of Planet Earth from the Southern hemisphere. 


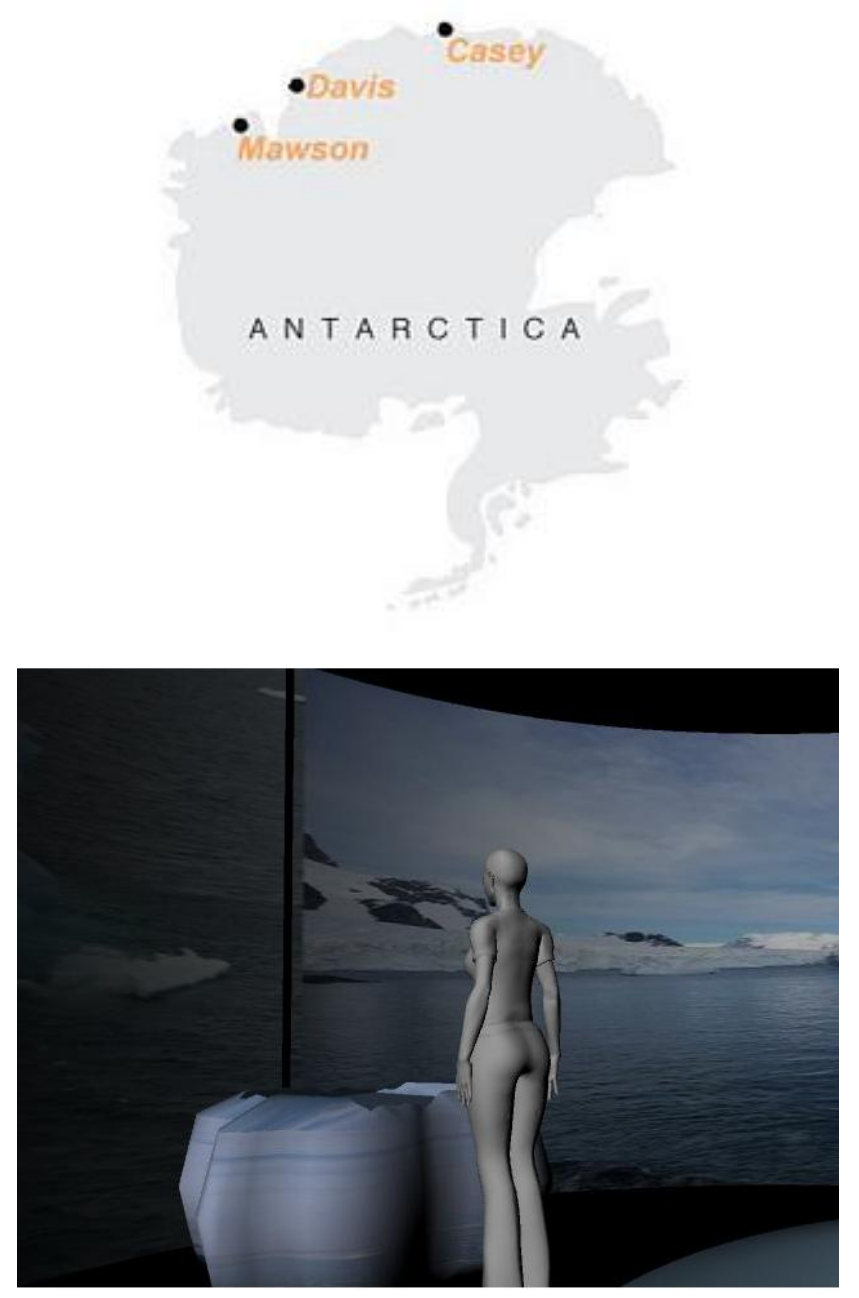

Fig. 2. (Top) Map of Antarctica. (Bottom) A viewer in the museum approaching a TUI table.

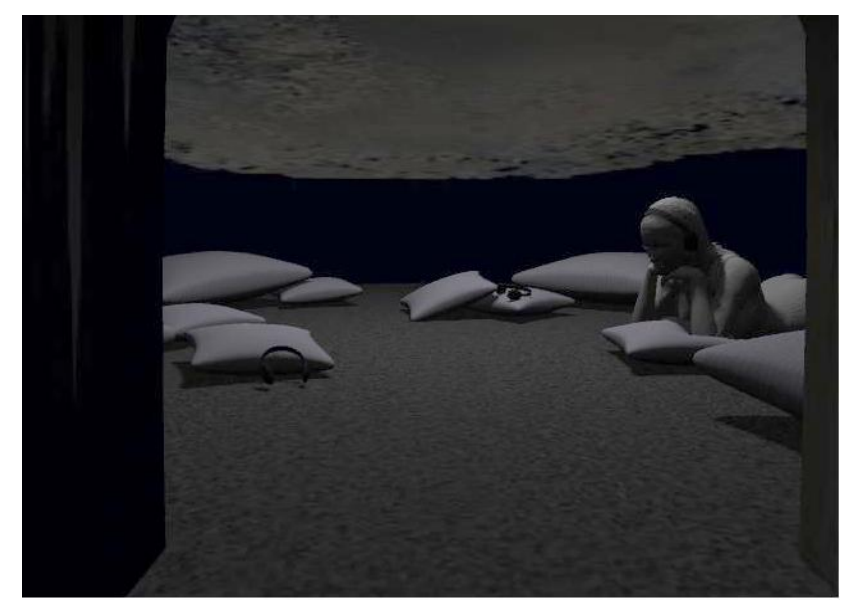

Fig. 3. A viewer inside the dome listening to Antarctic compositions.

The interior is large enough for several museum viewers to walk inside and sit down. Sitting inside viewers can put on headphones and listen to Antarctic compositions. The compositions are derived from raw Antarctic sound data. Inside museum visitors can view the globe visualization, undergoing real-time modification by other viewers outside in the main installation space.

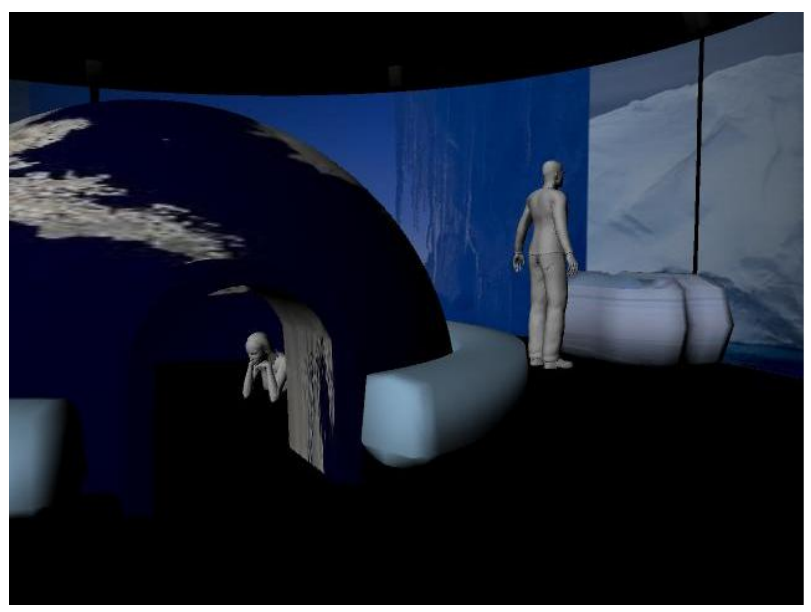

Fig. 4. (left) Dome. (right) viewers interact with the TUI fidicial markers, transforming the visualization on the outside of the dome.

\subsection{Dome visualization}

The dome-like visualization of Antarctica in the centre of the installation is based on concepts from the field of information visualization. Visualizations can represent largescale scientific data using graphical techniques to help understand and analyze scientific data sets: "Information visualization (or infovis) seeks to augment human cognition by leveraging human visual capabilities of abstract information, providing means by which humans with constant perceptual abilities can grapple with increasing hordes of data" [3]. Elena Zudilova-Seinstra et al. have argued that without the use of some form of interactivity, it is more difficult for users to perceive and understand data: "Users need to manipulate and explore the data. The way people perceive and interact with visualizations can strongly influence their understanding of the data as well as the usefulness of a visualization system" [4].

The museum user will visually understand data sets, by their interaction with objects on the TUI tables. On picking up an object, the visualization will display global sea-level rise. The visualization will be manipulated gesturally by multiple users interactions with objects on the TUI tables (see Fig. 5). The user can thus, interact with objects altering the visualization on of the domes surface. When a user grasps an object on the TUI table (attached to a fiducial marker) the visualization simulates the Earths ice masses disappearing from the effect of global warming.

There is scientific data indicating that sea-ice around East Antarctica has been diminishing since the 1950 s by a consistently greater extent than the previous 150 years [1]. The visualization is a direct translation of data of the effect of sea-level rise. Climatologist Jonathan T. Overpeck et al. claims that: "Sea-level rise from melting of polar ice sheets is one of the largest potential threats of future climate change" [5]. By collaborating with environmental scientists and the Australian Antarctic Division, we can create a museum environment, which acts as a vehicle to display significant climate change data to a wide public audience. 


\subsection{Tangible user interface tables}

The artistic realization of the tables is based on the technology of tangible user interface (TUI). TUI is a user interface in which a person can interact with digital information through the physical environment. In the field of Human Computer Interaction (HCI), Hiroshi Ishii pioneered TUI. Ishii, a professor in the MIT Media Laboratory is head of the Tangible Media Group. Ishii's notion for TUI is about giving physical form to digital information, known as tangible bits; the bits can be manipulated and are perceptible. In general, graspable and tangible interfaces are systems relating to the use of physical artifacts as representations and controls for digital information. A principal attribute of tangible interfaces is the seamless incorporation of representation and control with physical objects.

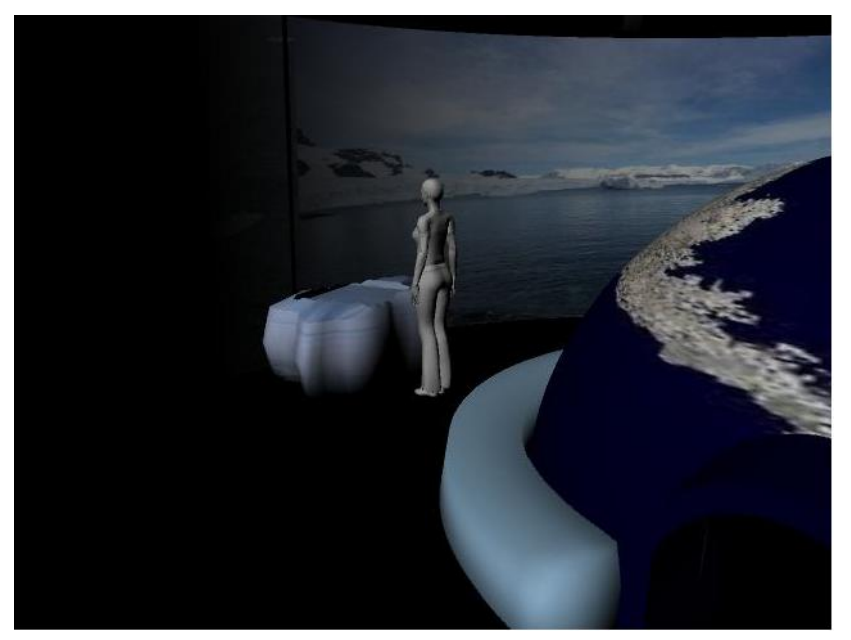

Fig. 5. A viewer standing in front of a TUI table, users control and move sound around the space, interacting with objects, modifying the dome visualization.

We are currently using reacTIVision, an open source, cross-platform computer vision tracking framework for fast and robust tracking of fiducial markers. ReacTIVision was designed to track specially designed fiducial markers. By developing to incorporate (real-time sound and image manipulation users will experience multi-touch tracking, by attaching fiducial markers to the objects on the TUI tables (see Fig. 5). ReacTIVision was developed as a toolkit for table-based tangible user interfaces and multi-touch interactive surfaces. ReacTIVision was designed by Martin Kaltenbrunner and Ross Bencina at the Music Technology Group at the Universitat Pompeu Fabra in Barcelona, Spain.

The toolkit reacTIVision was used for reacTable [6], an innovative electronic music instrument with a table-top multitouch tangible user interface. The reactable is an electronic music instrument with a tabletop tangible multi-touch interface: "Several simultaneous performers share complete control over the instrument by moving and rotating physical objects on a luminous round table surface. By moving and relating these objects, representing components of a classic modular synthesizer, users can create complex and dynamic sonic topologies, with generators, filters and modulators, in a kind of tangible modular synthesizer or graspable flowcontrolled programming language" [6]
InterANTARCTICA has two TUI tables. On each table there are 5 objects. Table 1 . features cards that have 'positive' effects on climate change: a power saver light globe; a tree sprout; a bike and a nuclear power plant. Table 2. features objects that have 'negative' effects on climate change: a light globe (non-energy efficient); a chainsaw; an air-conditioner; a car and a coal power plant (see Fig 6).

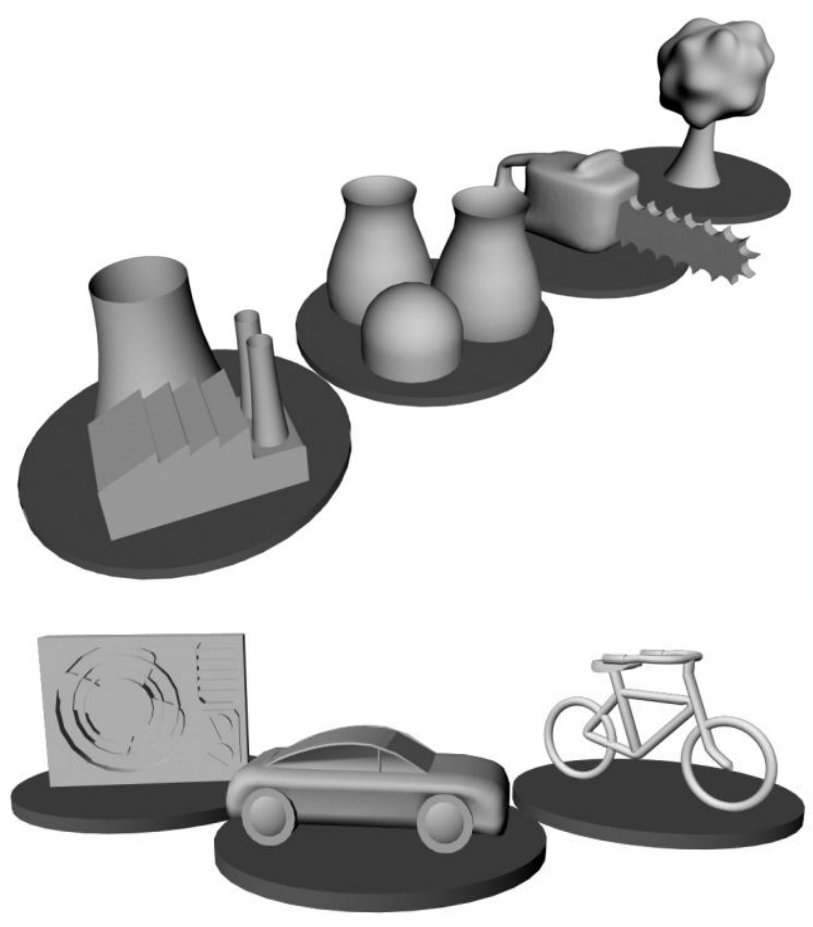

Fig. 6. Objects tracked to fidical markers on TUI tables.

\subsection{Sound Interaction}

By moving objects, on the TUI tables in the museum, viewers generate real-time music composition, derived from their gestural movements of the objects. The viewer in the museum space can 'grasp' the objects on the two tables, situated inside the installation. On picking up an object the viewer interactively controls and creates sound, moving it around the museum space. Movements of markers around the table will create sound by moving it around the space.

The TUI system will analyze live video and search for predefined fiducial markers. The museum viewer cannot see the fiducial markers (which are hidden beneath the objects situated around the tables). On picking up an object the viewer creates live music composition outputted around the museum space. The fiducial markers have six degrees of movement: X, Y, Z (height), yaw, pitch and roll. On recognizing a marker, the TUI connects to the audio application SuperCollider 3.2. SuperCollider is a real-time audio synthesis and algorithmic composition. The soundprocessed audio files will be diffused through a multiplechannel sound system. On picking up an object the viewer also controls the digital contents through gesture-driven interaction from the physical environment, as well as altering the data visualization projected onto the surface of the dome. 


\section{TECHNOLOGICAL OUTLINE: TANGIBLE INTERFACE TABLE}

Tangible Use Interface has been applied for urban design [7] [8], urban planners [9] [10] and feasibility studies [11]. Visual apprehension of distance and spatial depth would not be possible at all without the cooperation of the haptic memory [12]. From this perspective, vision needs the complementation from touch, which provides sensations of 'solidity, resistance, and protrusion' [12]. Therefore, if vision is separated from touch, humans could hardly estimate the distance [12]. Human scale and interaction are successful architecture [13]. Gibson [14] and Casey [15] dealt with space as a fundamental dimension of our being and acting in the world.

Physicality is identified as a critical feature from TUI for the installation presented in this paper. Multi-disciplinary knowledge is combined towards the central physicality [16]. Typically, ordinary physical objects have inanimate, nonmechanical and natural properties. Three aspects are extended further from these properties: directness of effort, locality of effort and visibility of state [16]. These aspects can further explain that tactile feedback from TUI systems can afford augmented experience. If TUI system design does not comply with the principles behind these properties and aspects, confusion, disinterest or reflection might occur. These properties lead to identification of centre-movementexpression (see Fig. 7).

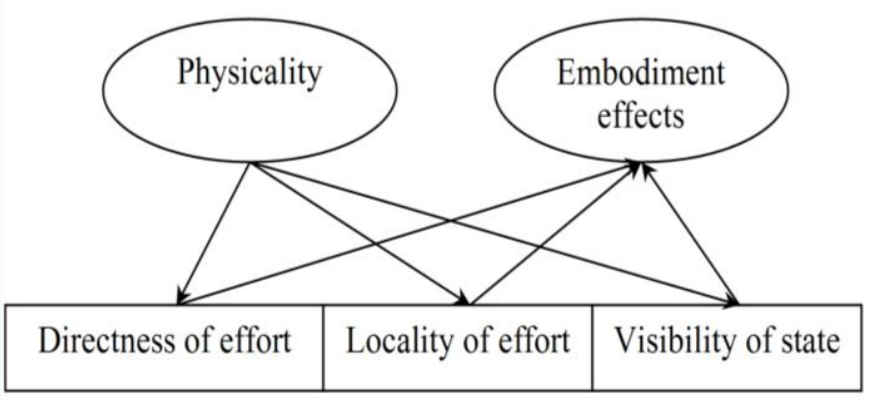

Fig. 7. The physicality between cause and effect.

Spatiality is another important property of TUI systems, which provides spaces for actions. This is different from traditional desktop systems that usually adopt a low congruent input device such as mouse and/or keyboard. In contrast, TUI systems provide opportunities to capitalize on human's developing repertoire of physical actions and spatial abilities for highly congruent input. For instance, interactive museum exhibitions embrace a long tradition of offering environments that emphasize human's actions and movement.

Embodiment in the context of cognitive science suggests that there exist certain strong correlations between physical activity and cognition [17]. TUI systems are envisaged to increase users' physical activities, which could in turn influence the corresponding cognitive process [18]. When people touch physical materials from TUI, perceptual and motor responses can be supplementary information for a more accurate assessment of the current situation. Such multisensory channels could in turn couple the perceptual and cognitive processes together. Computation and information are always physical [19]. The embodiment of the human is critical to understand cognition. The critical features of computation involved in physical embodiment are illustrated in Fig. 8. Pragmatic action involves manipulating physical entities to directly accomplish a task [17]. In contrast, epistemic actions are the ones to manipulate physical entities to change the nature of the necessary cognitive operations to complete a specific task.

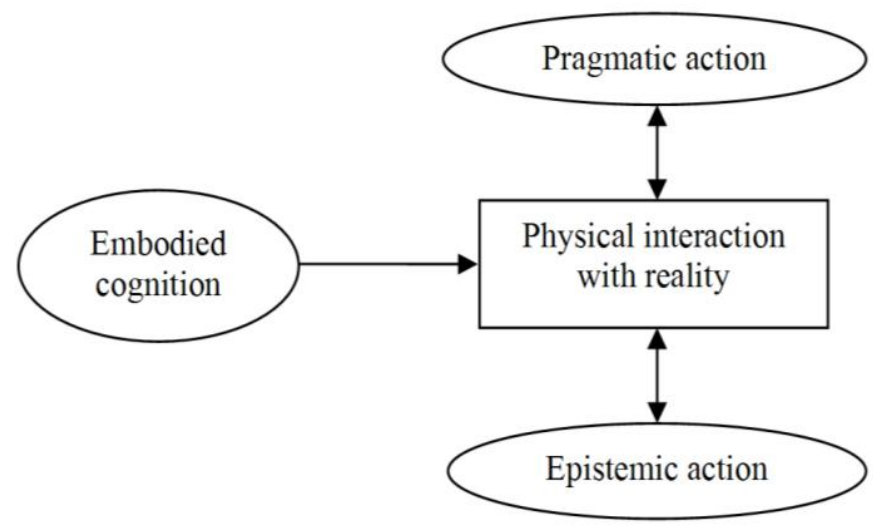

Fig. 8. The relation between the physical worlds to the embodied cognition

The TUI discussed in this paper is conceptualized as shown in Fig. 9. One of the advantages of this design is to emphasize the physical interaction with the real world as implied by embodied cognition. The overall architecture includes displaying the event and message flow among the sub-components of the system. It consists of the context server for managing the main logic, the dome projection and the tangible interfaces for user navigation and interaction. The context server includes the communication manager for the event and message handling among the sub-systems. It also contains user interaction and event processing modules for state update by the context server and the tangible interfaces. The tangible board interface adopts the game metaphor through which users can change the sound using various tangible blocks (tangible hexahedral objects). Each block's position could be detected by micro-controller driven switch unit. Each micro-controller cell unit controls LEDs and switches. The board interface is connected to the communication manager by TCP. RFID (Radio Frequency Identification) technology could also be used which typically consists of RFID tags and RFID readers. RFID refers to a branch of automatic identification (auto ID) technologies in which radio frequencies are used to capture and transmit data. A RFID tag is mounted onto one object and signals can be received by readers via antenna. The physical objects with embedded RFID tags can be arranged on the manipulation table. Those tags are read/write (R/W) tags in which additional data can be written by overriding or extending the existing data stored in the tags. RFID antenna and reader collect and transmit the radio-frequency (RF) signal. It is embedded into the mobile computing unit. The reader may also be portable as an attachment to the computing unit. 


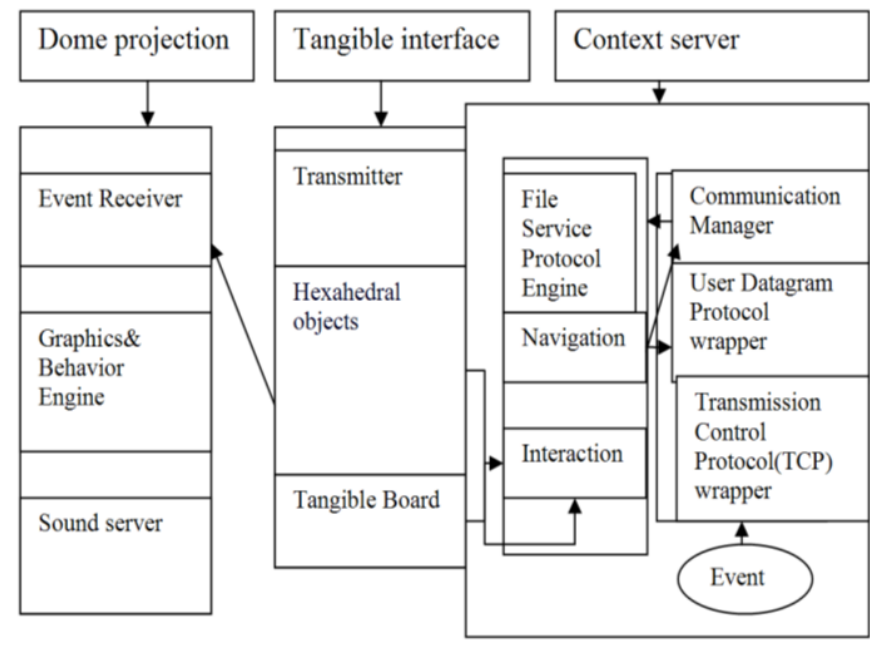

Fig. 9. System design

\section{INTERANTARCTICA MUSEUM CONCEPT}

The concept of the museum display is focused on the largest ice mass on Planet Earth, Antarctica. Antarctica covers over 900,000 square kilometers. Our motivation for this museum installation stems from an urgency to understand: "What has been labeled humanity's greatest challenge and our greatest threat: climate change" [1]. The museum installation provides an innovative technological platform for the public to interact, experience and gain vital knowledge about climate change.

The environment in Antarctica is the coldest, driest and windiest continent in the world. Ice cores taken from Antarctica provide a history into climate change because the ice contains records of past climate and atmospheric changes. Ice cores "show large fluctuations in temperature and atmospheric gases stretching back over 650,000 years" [1]. Currently, scientists are endeavoring to sample ice core dating back over 1,000,000 years. Understanding the environment in Antarctica is of global significance since the earth's environment is changing as a result of human activity [20].

Scientists Thomas Karl and Kevin Trenberth argue that climate change is dominated by human influences [21]. Alarmingly scientists have predicted that 'abrupt climate change' could occur: "...in the next hundred years or beyond" [21]. Abrupt climate change is a change in climate so widespread and can take place suddenly and unexpectedly. This means that human and natural systems have difficulty adapting.

The installation seeks to expand knowledge through the synthesis and presentation of climate change research in an interactive museum context. Professor Bruce Mapstone, argues that recent climate changes are unusual and unprecedented within the last million years: "We now have clear evidence that the atmosphere is getting progressively warmer, landmasses are becoming dryer in some places and wetter in others, the ocean surface is warming, glaciers are melting, and species distributions are changing on land and in our oceans" [1]. Antarctic science is instrumental for measuring the effect of climate change on Planet Earth.

\section{CONCLUSION}

InterANTARCTICA not only forms a part of interactive museum installation art, but is also a part of the environmental art movement. Environmental art refers to art dealing with ecological issues and can be traced by to the late 1960s. The movement has been associated with sculptural installation based art movements such as: Arte povera, Sitespecific art and Land art. InterANTARCTICA goes one step further from a broader context of installation art and environmental art to the use of viewer-based interactive art. From a background in installation and environmental art InterANTARCTICA's use of TUI enables viewers to become a part of the work itself.

InterANTARCTICA considers climate change in an interactive context, thus reinventing installation art in an experiential multi-modal context (sight, sound, touch). The German philosopher Martin Heidegger affirms that 'every work of art says something other than the mere thing itself is' [22]. InterANTARCTICA interacts with installation art, environmental art and viewer-based interactivity in Heidegger's sense and speaks to all these practices.

In the following passage, Mikhail Bakhtin, Russian philosopher and literary critic cites Fyodor Dostoevsky's ability to communicate in dialogic discourse beyond his epoch: "Dostoevsky possessed an extraordinary gift for hearing the dialogue of his epoch, or more precisely, for hearing his epoch as a great dialogue, for detecting in it not only individual voices, but precisely and predominantly the dialogic relationship among voices, their dialogic interaction..." [23]. Like Bahktin's reading of Dostoevsky [24], InterANTARCTICA forms a 'dialogic relationship' via multi-modal interaction with the museum participants (sound, image, touch). Equally, it is the viewer who navigates through the space and forms a dialogic relationship with the issue presented (climate change), this issue is critical to and extending beyond this epoch. Museum interactive art, like Dostoevsky's important work, creates a channel of communication for future ideas.

Environmental scientists have argued need for multidisciplinary research to combat climate change: "Modern climate science requires contributions from atmospheric physicists and chemists, meteorologists, geologists, oceanographers, hydrologists, glaciologists, biologists, mathematicians, geographers, modelers and others" [1]. InterANTARCTICA is made up of what Mapstone defines as 'others' from various fields: visual art; computer science; sound art; design computing and environmental science, by promoting awareness about the urgency to address climate change. Daniel J. Sandin et al in "The Artist and Scientific Research Environment" [25] reflected on the experiences of collaboration between artist and scientists, outlining measures that enable artists and computer scientists to benefit from collaborations. Since we have never faced a similar global-based problem (climate change), the need for interdisciplinary collaboration is highly significant and should continue to grow in the future. 
InterANTARCTICA will give museum visitors the opportunity to learn about climate science in an entertaining, interactive and visually sophisticated means. Furthermore, the museum installation's use of visualization and TUI technologies will help museum visitors understand critical scientific data surrounding climate change and the adverse effects of global sea-level rise.

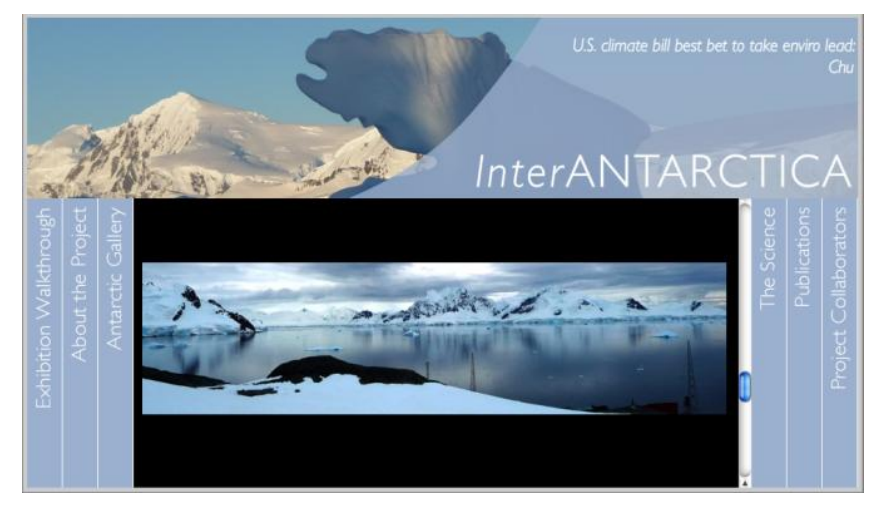

Fig. 10. www.InterANTARCTICA.com, website for Museum Project.

\section{ACKNOWLEDGEMENTS}

Dr Martin Tomitsch, HCI Designer; Michael Bates, Sound Designer and Composer; Design Computing Students, Emma Chee, Kevin Kuan-Yu, Drew Cosgrove, Nathaniel Fay, Andrew Kurniawan, Eric Neo, Suna Rizalar, Lucy Ro, Ka Florence Sze-To, Julia Tang, Patrick Wang; Dr Estelle Lazer, Archaeologist; Rob Hutchinson, Photographer: Bruce Hull, Environmental Officer at the Australian Antarctic Division and the Australian Antarctic Division. Special thanks to Emma Chee for the virtual models of the installation.

\section{REFERENCES}

[1] B. Mapstone, Climate Change and the Importance of Multidisciplinary Science in Antarctica, Commonwealth of Australia, Melbourne, 2007.

[2] e. a. Meehl, "How Much More Global Warming and Sea Level Rise?," Science, vol. 307, no. 5716, pp. 1769-1772, 18 March, 2005.

[3] C. S. K. Heer J., Landay J., "Prefuse: a toolkit for interactive information visualization," in ACM Human Factors in Computing Systems CHI, 2005.

[4] E. A. Zudilova-Seinstra, "Overview of Interactive Visualization," Interactive Visualization, pp. 3-15, London: Springer.

[5] J. T. Overpeck, et al, "Paleoclimatic Evidence for Future Ice-Sheet Instability and Rapid Sea-Level Rise," Science, vol. 311, no. 5768, pp. 1747-1750, 24 March, 2006.

[6] M. K. Sergi Jordà, Günter Geiger and Marcos Alonso, "Reactable."

[7] B. Ullmer, and Ishii H., "The metaDESK: Models and Prototypes for Tangible User Interfaces."

[8] J. Underkoffler, and Ishii H., "Urp: A Luminous-Tangible Workbench for Urban Planning and Design." pp. 386-393.

[9] M. Billinghurst, and Kato, H., "Collaborative Mixed Reality." pp. 261284.

[10] V. Buchmann, et al, "FingARtips: gesture -based direct manipulation in Augmented Reality." pp. 212-221.

[11] R. Freeman, and Steed A., "Interactive Modeling and Tracking for Mixed and Augmented Reality," in VRST'06, 2006.

[12] S. Houlgate, "Vision, Reflection, and Openness- The "Hegemony of Vision' from a Hegelian Point of View," University of California, Berkeley, 1993.
[13] J. Gehl, Life between buildings: using public space, New York: Van Nostrand Reinhold, 1987.

[14] J. J. Gibson, "Observations on Active Touch," Psychological Review, vol. 69, no. 6, pp. 477-490, 1962.

[15] E. S. Casey, "The Fate of Place," A Philosophical History, Berkeley: University of California Press, 1997.

[16] A. Kamaruddin, and Dix, A., "Understanding Physicality on Desktop: Preliminary Results," Physicality First International Workshop on Physicality, D. R.-E. M. Ghazali, E. Hornecker and A. Dix ed., pp. 3941, 2006.

[17] L. W. Barsalou, et al, "Social embodiment," The Psychology of Learning and Motivation, 2003.

[18] L. W. Barsalou, and Wiemer, H.K., "Situating abstract concepts," Grounding Cognition: The Role of perception and Action in Memory, Language, and Thought, D. a. Z. Pecher, R. , ed., Cambridge: Cambridge University Press, 2005.

[19] A. N. Antle, "Child-based personas: need, ability and experience. Cognition, Technology and Work," Methodological Research, vol. Special Issue on Child Computer Interaction, 2007.

[20] A. A. Division. "Human Impacts in Antarctica," 2009; http://www.aad.gov.au/default.asp? casid=3436.

[21] R. Thomas, Karl., Trenberth, K., "Modern "Global Climate Change"," Science, vol. 302, no. 5651, pp. 1719-1723, 2003.

[22] M. Heidegger, "Poetry, Language, Thought," New York: Harper \& Row, 1971.

[23] M. Bakhtin, "Problems of Dostoevsky's Poetics," The Bakhtin Reader: Selected Writings of Bakhtin, Medvedev and Voloshinov, P. Morris, ed., London: Oxford University Press, 1963.

[24] M. Bakhtin, Problems of Dostoevsky's Poetics, Minneapolis: University of Minnesota Press, 1984.

[25] D. J. Sandin, et at, "The Artist and the Scientific Research Environment," Leonardo: Journal of the International Society for the Arts, Sciences and Technology, vol. 39, no. 3, pp. 219-221, June, 2006.

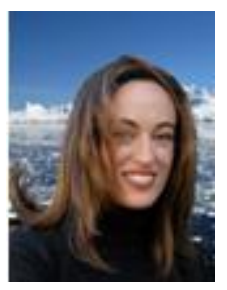

Dr Caitilin de Bérigny Wall (onacloV) is Project Director. onacloV designed and is leading the research project InterANTARCTICA. onacloV is an artist, researcher and Lecturer at the University of Sydney, Australia. onacloV's research explores technology within the context of installation in museum, gallery and architectural space. onacloV undertook her $\mathrm{PhD}$ from the University of Canberra. Her other degrees include a Bachelor of Arts (Visual) with Honours from the Australian National University and the École Nationale Supérieure des Beaux-Arts, Paris, France. She has also obtained a Post Graduate Diploma in Video Art \& Contemporary Theory and Philosophy from the École des Beaux-Arts, Marseille, France. Her artworks have been exhibited extensively, nationally in Australia and internationally in France and the USA. onacloV has directed and produced a number of documentaries, which have been aired on television and displayed in multiple-channel video installations environments in art galleries and museums.

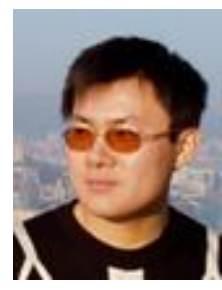

Dr. Xiangyu Wang is Lecturer in Design Computing at the Faculty of Architecture, Design \& Planning, at the University of Sydney. He obtained his Ph.D. degree in Civil Engineering at Purdue University in 2005. Dr. Wang's work is featured with highly interdisciplinary research across Design, Computer Engineering, Construction, and Human Factors. His specific research interests include virtual environments for design, human-computer interactions, computer-supported cooperative work, and construction automation and robotics. He is now supervising five Ph.D. students and has published over 140 refereed articles into a wide range of highly recognized international journals and conferences (ASCE, IEEE, ACM, etc.). He was also awarded a US National Science Foundation grant to investigate skill development through virtual technologies. 